\title{
One-Year Results of the Use of Absorb Bioresorbable Vascular Scaffold in Patients with Different Forms of Coronary Artery Disease as Compared to a Drug-Eluting Stent
}

\author{
Nabijon P. Yuldashev, $\mathrm{PhD}^{1 *}$; Robert J. Gil, $\mathrm{PhD}^{2,3}$; Ravshanbek D. Kurbanov, $\mathrm{PhD}, \mathrm{ScD}^{1}$ \\ ${ }^{1}$ Republican Specialized Center of Cardiology, Tashkent, Uzbekistan \\ ${ }^{2}$ Central Clinical Hospital of the Internal Affairs and Administration Ministry, Warsaw, Poland \\ ${ }^{3}$ Mossakowski Medical Research Centre, Polish Academy of Science, Warsaw, Poland
}

\begin{abstract}
The aim of this study was to evaluate the immediate and long-term (12 months) clinical and angiographic efficacy of myocardial revascularization using Absorb GT1 Bioresorbable Vascular Scaffold (BVS) in comparison to second-generation drugeluting stent (DES) in patients with various forms of coronary artery disease (CAD).

Material and Methods: The study included 152 patients with CAD. There were 131 men and 32 women with an average age of $54.6 \pm 10.4$ years. Patients' data were evaluated retrospectively from the medical records.

Results:

- Implantation of BVS in patients with different forms of CAD did not cause any angiographic or clinical complications, either at the hospital or at 12-month observation stages, and the results were comparable to those of the DES group.

- The technique of implanting BVS and the reception of dual antiplatelet therapy are the key factors for achieving positive results in real clinical practice.

- The use of BVS-frameworks contributes to improving clinical, functional and laboratory indicators, while the observed positive dynamics are comparable to similar data of the DES group.

- Regardless of the type of implanted stents, the survival rate among CAD patients within 12 months after stenting was $100 \%$, while none of the respondents during this time developed acute MI or recurrence of angina attacks. (International Journal of Biomedicine. 2018;8(1):20-25.)
\end{abstract}

Key Words: Absorb bioresorbable vascular scaffold $\bullet$ drug-eluting stent $\bullet$ coronary artery disease $\bullet$ dual antiplatelet therapy

\section{Abbreviations}

CAG, coronary angiography; CAD, coronary artery disease; $\mathbf{C h}$, total cholesterol; DAT, dual antiplatelet therapy; DES, drugeluting stent; FC, functional class; HDL, high-density lipoprotein; LDL, low-density lipoprotein; LVEDV, left ventricular end-diastolic volume; LVESV, left ventricular end-systolic volume; LVEF, left ventricular ejection fraction; MI, myocardial infarction; MACE, major adverse cardiac events; PCI, percutaneous coronary interventions; PTCA, percutaneous transluminal coronary angioplasty; TBA, transluminal balloon angioplasty; TG, triglyceride; VLDL, very low-density lipoprotein.

\section{Introduction}

In recent years, in some developed countries, there has been a trend towards a reduction in mortality from CAD. This is due to the improvement of preventive measures for CAD, as well as

*Corresponding author: Nabijon P. Yuldashev, PhD. Republican Specialized Center of Cardiology, Tashkent, Uzbekistan. E-mail: nabi1975@mail.ru the wide introduction of new effective methods for its diagnosis and treatment. In the USA, where about 4 million people suffer from $\mathrm{CAD}$, despite an improvement in survival rates, more than 650,000 die each year. According to a prognosis by American scientists, by 2020 cardiovascular diseases will account for about $36 \%$ of deaths..$^{(1)}$ Thus, the fight against CAD is one of the primary tasks of the medicine in the twenty-first century.

In the last century, one of the most important achievements of cardiology was the development by Andreas Grüntzig 
of the technique of TBA, ${ }^{(2)}$ which allows the elimination of stenotic lesions of the coronary artery with minimal surgical trauma during endovascular intervention. Practical interest in interventional cardiology has increased significantly with the advent of coronary prostheses - stents. The use of the stenting technique with unsatisfactory angiographic results of the TBA procedure (residual stenosis or coronary artery dissection) significantly reduced the incidence of complications from endovascular treatment of CAD. ${ }^{(3)}$

Currently, stenting of coronary arteries has a dominant position among other endovascular methods for CAD treatment. The introduction of the stenting procedure significantly improved not only the immediate but also the long-term (halfyear) results of endovascular treatment of CAD in comparison with TBA. ${ }^{(4)}$ At the beginning of the century, stents with an antiproliferative coating were developed and introduced into clinical practice. However, despite many achievements in this area, a number of problems remain: development of neointimal hyperplasia inside the stent, stent thrombosis, and neoatherosclerosis followed by the development of late and very late thrombosis. . $^{(5,6)}$

In this regard, the prospect of using a temporary vascular stent has become very important. However, on March 18, 2017, the FDA issued a letter to health care providers treating patients with Absorb GT1 Bioresorbable Vascular Scaffold (BVS) that there is an increased rate of MACE observed in patients receiving the BVS, when compared to patients treated with the approved metallic XIENCE DES. (7) On October 31, 2017, the FDA issued an update to the March 18, 2017 letter to health care providers to inform the health care community that interim study results through three years from the pivotal clinical trial (ABSORB III) continue to show an increased rate of MACE and BVS scaffold thrombosis in patients receiving the Absorb GT1 Bioresorbable Vascular Scaffold (BVS), when compared to patients treated with the approved metallic XIENCE drug-eluting stent. ${ }^{(8)}$

The above-mentioned data, as well as the experience of our clinic in the endovascular treatment of CAD, determined the purpose of this study: to evaluate the immediate and long-term (12 months) clinical and angiographic efficacy of myocardial revascularization using Absorb GT1 BVS in comparison to second-generation DES in patients with various forms of CAD.

\section{Materials and Methods}

In our clinic, 152 patients with $\mathrm{CAD}$ were examined. There were 131 men and 32 women with an average age of $54.6 \pm 10.4$ years.

Patients' data were evaluated retrospectively from the medical records:

- General clinical and laboratory blood tests, including blood levels of Ch, TG, HDL, VLDL, and LDL

- ECG in 12 standard leads

- Echocardiography with determination of LVEDV, LVESV, and LVEF

- CAG was performed using Phillip Allura CV20 (Phillips Medical Systems, The Netherlands)

- Invasive intervention was performed by right transradial access according to L.Campeau. ${ }^{(9)}$ Selective catheterization of the coronary arteries was performed with Judkins and Amplatz coronary catheters. The contrast agent "Unigexol-350" ("Unique", India) was used. All information was stored on the hard disk of the computer system with the subsequent export of information for processing and storage in the Xcellera system of the local computer network of the catheterization laboratory.

- In collegial analysis of CAG data, we determined the type of coronary blood supply and noted the number of affected coronary arteries, localization, and type of stenotic narrowing. To assess the risk of PCI, each SYNTAX score was calculated on an individual basis using an online calculator.

- The Quality of Life of patients was assessed using the SF36 questionnaire.

- The condition of patients in the dynamics was assessed 3,6, 12 and 24 months after CAG; some patients repeated CAG with a pharmacological test after 12 and 24 months.

Depending on the type of implants, two groups of patients were formed. Group 1 included 78 patients with implanted BVS; Group 2 included 74 patients with DES stents. BVS implantation was performed according to the following set of rules:

1) Prepare the site of the lesion for pre-dilatation with a balloon in a ratio of 1:1 to the diameter of the vessel.

2) Correctly choose the diameter of the scaffold to avoid its overstretch in the vessel.

3) Take into account disclosure limits.

4) Perform post-dilation with a high-pressure balloon catheter.

5) Use DAT.

In this review, we present one-year results of the study.

The inclusion criteria:

- CAD determined by the results of the clinical and instrumental examination. Written informed consent obtained from each patient.

- Documented painless ischemia, stable and unstable angina, acute MI and MI history

- De novo native coronary artery lesions

- Coronary artery lesions, allowing a stent to be implanted

- Hemodynamically significant coronary artery stenosis $(\geq 70 \%)$ The exclusion criteria:

- Previous PCI with stenting or aorto-coronary artery bypass graft in history

- Severe concomitant pathology of the cardiovascular system (aortic aneurysm, valvular pathology requiring surgical correction, severe left ventricular systolic dysfunction (EFLV $<35 \%$ ), decompensated heart failure).

- Intolerance to anticoagulants / disaggregants.

- Bifurcation lesions or lesion of the coronary artery trunk

- Cardiogenic shock.

- Moderate and high risk PCI on SYNTAX score The primary endpoints:

1) Sudden cardiac death

2) MI associated with the target artery

3) Revascularization of the target vessel according to clinical indications 
4) Recurrent/progressive angina

5) Stent thrombosis (definite, probable, or possible)

The statistical analysis was performed using the statistical software «Statistica» (v6.0, StatSoft, USA). To determine whether the compared groups of patients share the same distribution of a single categorical variable, the "test of homogeneity" was applied. Baseline characteristics were summarized as frequencies and percentages for categorical variables and as mean $\pm \mathrm{SD}$ for continuous variables. Analysis of the distribution of values obtained was performed using the Kolmogorov-Smirnov test. Student's unpaired t-test was used to compare two groups for data with normal distribution. Differences of continuous variables departing from the normal distribution were tested by the MannWhitney U-test. Group comparisons with respect to categorical variables are performed using chi-square tests. Pearson's correlation coefficient $(r)$ was used to determine the strength of the relationship between the two continuous variables. A probability value of $P<0.05$ was considered statistically significant.

\section{Results}

At the initial stage of the study, the groups were comparable in anthropometric, clinico-laboratory and functional parameters, as well as in the nosological structure. However, according to the manufacturer's recommendations for the installation of BVSframes, mainly for young patients, our emphasis was placed on the age of the respondents. In this connection, the only difference between the groups was in the ages of the participants (Table 1, Figures 1 and 2).
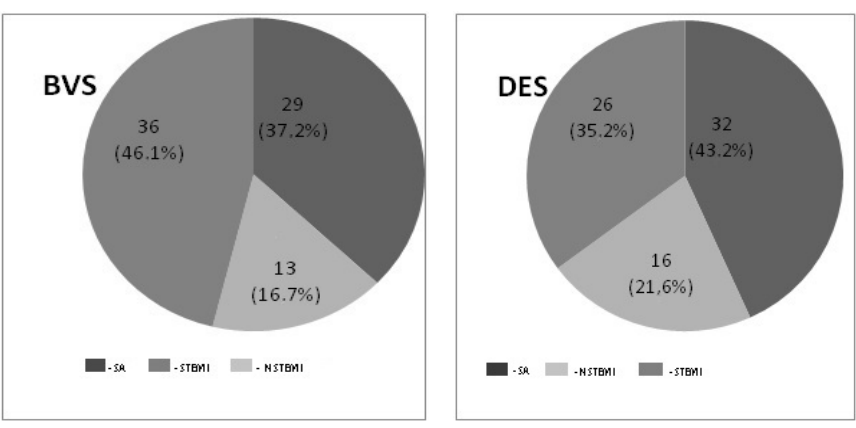

Fig. 1. Nosological structure of the compared groups of patients. SA-stable angina pectoris; (NSTEMI-non-ST-segment elevation MI; STEMI-ST-segment elevation MI.

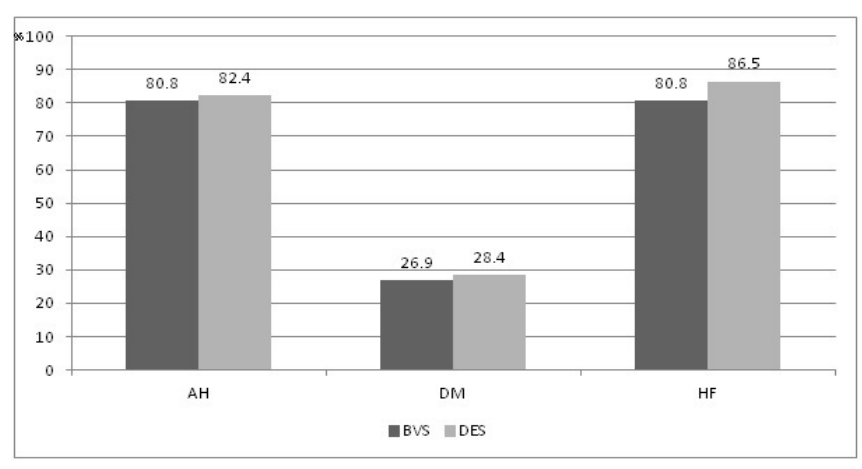

Fig. 2. Comorbid conditions.

AH - arterial hypertension; DM - diabetes mellitus type 2; HF chronic heart failure. The data is presented as a percentage.
Table 1.

Anthropometric, clinico-laboratory and functional characteristics of the patients of the compared groups at the initial stage of the study

\begin{tabular}{|c|c|c|c|}
\hline \multicolumn{2}{|c|}{ Variable } & Group 1 & Group 2 \\
\hline \multicolumn{2}{|c|}{ Age. years } & $51.83 \pm 10.59$ & $57.74 \pm 9.33 *$ \\
\hline \multirow{2}{*}{ Gender } & male & $69(88.5 \%)$ & $62(83.8 \%)$ \\
\hline & female & $9(11.5 \%)$ & $12(16.2 \%)$ \\
\hline \multicolumn{2}{|c|}{ Height, cm } & $1.71 \pm 0.07$ & $1.70 \pm 0.07$ \\
\hline \multicolumn{2}{|c|}{ Weight, kg } & $87.04 \pm 13.09$ & $87.49 \pm 14.03$ \\
\hline \multicolumn{2}{|c|}{ BMI, kg/m² } & $29.76 \pm 3.84$ & $30.33 \pm 4.43$ \\
\hline \multicolumn{2}{|l|}{$\mathrm{Hb}, \mathrm{g} / \mathrm{l}$} & $128.2 \pm 14.0$ & $129.3 \pm 17.4$ \\
\hline \multicolumn{2}{|c|}{$\mathrm{Ch}, \mathrm{mg} / \mathrm{dl}$} & $192.6 \pm 59.0$ & $180.7 \pm 45.1$ \\
\hline \multicolumn{2}{|c|}{$\mathrm{TG}, \mathrm{mg} / \mathrm{dl}$} & $227.1 \pm 160.3$ & $195.9 \pm 123.4$ \\
\hline \multicolumn{2}{|c|}{$\mathrm{HDL}, \mathrm{mg} / \mathrm{dl}$} & $35.6 \pm 8.6$ & $35.9 \pm 6.5$ \\
\hline \multicolumn{2}{|c|}{ VLDL, mg/dl } & $46.5 \pm 33.3$ & $39.2 \pm 24.7$ \\
\hline \multicolumn{2}{|c|}{ LDL, mg/dl } & $110.1 \pm 46.8$ & $105.6 \pm 35.9$ \\
\hline \multicolumn{2}{|c|}{ Glucose, mmol/l } & $6.1 \pm 1.9$ & $6.6 \pm 2.4$ \\
\hline \multicolumn{2}{|c|}{ CRP, g/1 } & $19.1 \pm 29.1$ & $23.2 \pm 48.5$ \\
\hline \multicolumn{2}{|c|}{ LVEDV, ml } & $150.7 \pm 33.9$ & $150.1 \pm 39.7$ \\
\hline \multicolumn{2}{|c|}{ LVESV, ml } & $64.7 \pm 27.4$ & $65.8 \pm 26.8$ \\
\hline \multicolumn{2}{|c|}{ IST, mm } & $10.4 \pm 1.4$ & $11.3 \pm 2.4$ \\
\hline \multicolumn{2}{|c|}{ LVPWT, mm } & $10.1 \pm 1.2$ & $11.3 \pm 1.4$ \\
\hline \multicolumn{2}{|c|}{ LVEF, \% } & $58.2 \pm 10.2$ & $57.3 \pm 7.7$ \\
\hline
\end{tabular}

*. $P=0.000 ; B M I$ - body mass index; $C R P$ - C-reactive protein; $H b$ - hemoglobin; IST- interventricular septum thickness; LVPWT-left ventricular posterior wall thickness.

Angiography between the compared groups of patients also showed no statistically significant differences, except for the mean diameter of the artery, which was larger in the BVS group (Table 2).

Table 3 presents information in the form of quantitative characteristics for implantation techniques. In Group 1, the number of affected segments of the coronary bed was 110, in Group 2 - 105. In groups 1 and 2, the number of implants was 108 (1.38 per patient) and 98 (1.32 per patient), respectively. By the time of exposure of stents, a significant difference was found: average exposure was greater in Group 1. Immediate, good angiographic success was noted in $100 \%$ of cases in both groups of patients; in all patients we were able to recanalize the occluded coronary artery segment. There were no complications in the form of dissection, the phenomenon of "noreflow," acute thrombosis in the stent, coronary artery perforation, etc. The success rate of the procedure also amounted to $100 \%$ in both compared groups.

In Group 1, good clinical success was identified in $94.8 \%$ of cases, and 4 patients had angina attacks at the level of FC I. In Group 2, clinical success was noted in $95.9 \%$ of cases, and 3 patients had angina attacks at the level of FC I-II. There were no lethal outcomes in either group. Thus, direct clinical and angiographic results, regardless of the type of implanted stents, did not have complications such as MACE.

The next stage of the study was the assessment of clinical, laboratory and functional characteristics of patients 1 year after PCI. 
Table 2.

Angiographic characteristics of the compared groups of patients

\begin{tabular}{|c|c|c|c|}
\hline \multicolumn{2}{|c|}{ CAG } & Group 1 & Group 2 \\
\hline \multicolumn{2}{|c|}{ Mean SYNTAX score } & $9.77 \pm 4.64$ & $10.36 \pm 4.92$ \\
\hline \multicolumn{2}{|c|}{$\begin{array}{l}\text { The average number of vascular } \\
\text { lesions }\end{array}$} & $1.46 \pm 0.64$ & $1.49 \pm 0.82$ \\
\hline \multicolumn{2}{|c|}{ 1-vascular lesion, n (\%) } & $46(59.0 \%)$ & $43(58.1 \%)$ \\
\hline \multicolumn{2}{|c|}{ 2-vascular lesions, n (\%) } & $32(41.0 \%)$ & $31(41.9 \%)$ \\
\hline \multicolumn{2}{|c|}{ Total number of implants } & 108 & 98 \\
\hline \multicolumn{2}{|c|}{$\begin{array}{l}\text { The average number of implants per } \\
\text { patient }\end{array}$} & 1.38 & 1.32 \\
\hline \multicolumn{2}{|c|}{ Mean lesion length, mm } & $30.27 \pm 17.19$ & $31.39 \pm 13.40$ \\
\hline \multirow{9}{*}{$\mathrm{ADA}$} & $\mathrm{n}(\%)$ & $68(87.2 \%)$ & $61(82.4 \%)$ \\
\hline & Mean $\%$ of stenosis & $89.17 \pm 9.43$ & $88.46 \pm 8.49$ \\
\hline & Average diameter, $\mathrm{mm}$ & $3.33 \pm 0.44$ & $3.46 \pm 0.35$ \\
\hline & Stenosis type A & 5 & 4 \\
\hline & Stenosis type B & 26 & 18 \\
\hline & Stenosis type $\mathrm{C}$ & 39 & 43 \\
\hline & The defeat of the $\mathrm{p} / 3$ & 52 & 41 \\
\hline & The defeat of the $\mathrm{m} / 3$ & 22 & 30 \\
\hline & The defeat of the $d / 3$ & 3 & 2 \\
\hline \multirow{9}{*}{$\mathrm{CA}$} & $\mathrm{n}(\%)$ & $10(12.8 \%)$ & $10(13.5 \%)$ \\
\hline & Mean $\%$ of stenosis & $82.50 \pm 15.17$ & $84.40 \pm 14.86$ \\
\hline & Average diameter, $\mathrm{mm}$ & $3.35 \pm 0.54$ & $3.15 \pm 0.49^{*}$ \\
\hline & Stenosis type A & 2 & 2 \\
\hline & Stenosis type B & 3 & 3 \\
\hline & Stenosis type $\mathrm{C}$ & 5 & 5 \\
\hline & The defeat of the $p / 3$ & 4 & 3 \\
\hline & The defeat of the $\mathrm{m} / 3$ & 6 & 6 \\
\hline & The defeat of the $d / 3$ & 2 & 1 \\
\hline \multirow{9}{*}{$\mathrm{RCA}$} & $\mathrm{n}(\%)$ & $28(35.9 \%)$ & $17(22.9 \%)$ \\
\hline & Mean $\%$ of stenosis & $79.03 \pm 15.59$ & $80.14 \pm 17.97$ \\
\hline & Average diameter, $\mathrm{mm}$ & $3.29 \pm 0.56$ & $3.06 \pm 0.59^{\wedge}$ \\
\hline & Stenosis type A & 1 & 4 \\
\hline & Stenosis type B & 14 & 8 \\
\hline & Stenosis type C & 11 & 5 \\
\hline & The defeat of the $p / 3$ & 10 & 6 \\
\hline & The defeat of the $\mathrm{m} / 3$ & 10 & 8 \\
\hline & The defeat of the $d / 3$ & 6 & 5 \\
\hline
\end{tabular}

$*_{-} P=0.018$ and $^{\wedge}-P=0.015$ (differencesbetweengroups);ADA-Anterior descending artery; $C A$ - Circumflex artery; RCA - Right coronary artery; $p / 3$ - proximal third; $m / 3$ - middle third; $d / 3$ - distal third.

The intra-group analysis showed highly valid progress in laboratory parameters. At the same time, according to echocardiography, there was a statistically significant increase in only LVEF in Group 2 (Table 4). Intergroup comparative analysis did not reveal statistically significant differences, which, in our opinion, is due to the same therapeutic effect of both BVS and DES. Figure 3 presents a clinical example of BVS implantation with a 12-month dynamic evaluation. Repeated CAG after 1 year was carried out in 5 respondents with implanted BVS, but no resorption of these devices was observed (Table 5).
Table 3.

Quantitative characteristics for implantation techniques (BVS/DES)

\begin{tabular}{|l|c|c|}
\hline \multicolumn{1}{|c|}{ Variable } & Group 1 & Group 2 \\
\hline Total number of lesions & 110 & 105 \\
\hline Defeats with L > 20mm & $33(42.6 \%)$ & $37(50.0 \%)$ \\
\hline Implantation of more than one skeleton & $32(41.0 \%)$ & $31(41.9 \%)$ \\
\hline Predilatation & $70(89.7 \%)$ & $64(86.5 \%)$ \\
\hline Mean diameter of the ball for predilution & $2.54 \pm 0.3$ & $2.57 \pm 0.4$ \\
\hline Mean pressure of the ball for predilution & $12.8 \pm 1.6$ & $13.1 \pm 1.7$ \\
\hline Average exposure t sec. & $50.8 \pm 1.7$ & $48.4 \pm 1.3 *$ \\
\hline Postdilation & $78(100 \%)$ & $74(100 \%)$ \\
\hline Total number of implanted scaffolds & 108 & 98 \\
\hline Mean length of scaffold & $24.4 \pm 10.3$ & $26.5 \pm 8.2$ \\
\hline Mean diameter of scaffold & $3.2 \pm 0.3$ & $3.3 \pm 0.5$ \\
\hline \multicolumn{2}{|c|}{ Type of post-dilatation balloon } \\
\hline High-pressure balloon & $65(83.3 \%)$ & $62(83.8 \%)$ \\
\hline Low pressure balloon & $13(16.7 \%)$ & $12(16.2 \%)$ \\
\hline $\begin{array}{l}\text { The average diameter of the balloon for } \\
\text { post-dilatation }\end{array}$ & $3.17 \pm 0.33$ & $3.29 \pm 0.53$ \\
\hline $\begin{array}{l}\text { The mean pressure of the balloon for } \\
\text { post-dilatation }\end{array}$ & $14.34 \pm 4.42$ & $14.33 \pm 4.45$ \\
\hline
\end{tabular}

$*_{-} P<0.05$ (differences between groups).

Table 4.

The assessment of clinical, laboratory and functional characteristics of patients 1 year after PCI (intra-group analysis)

\begin{tabular}{|c|c|c|}
\hline Variable & Initial data & After 12 months \\
\hline BVS & $\mathrm{n}=78$ & $\mathrm{n}=54$ \\
\hline $\mathrm{Ch}, \mathrm{mg} / \mathrm{dl}$ & $192.6 \pm 59.0$ & $188.8 \pm 55.2$ \\
\hline $\mathrm{TG}, \mathrm{mg} / \mathrm{dl}$ & $227.1 \pm 160.3$ & $135.2 \pm 33.2 * *$ \\
\hline HDL, mg/dl & $35.6 \pm 8.6$ & $37.8 \pm 4.8$ \\
\hline VLDL, mg/dl & $46.5 \pm 33.3$ & $27.0 \pm 6.8^{* *}$ \\
\hline LDL, mg/dl & $110.1 \pm 46.8$ & $124.0 \pm 54.6$ \\
\hline Glucose, mmol/1 & $6.1 \pm 1.9$ & $4.7 \pm 0.5^{* *}$ \\
\hline CRP, g/l & $19.1 \pm 29.1$ & $4.6 \pm 1.3 * *$ \\
\hline LVEDV, ml & $150.7 \pm 33.9$ & $129.1 \pm 28.6$ \\
\hline LVESV, ml & $64.7 \pm 27.4$ & $56.6 \pm 19.5$ \\
\hline IST, mm & $10.4 \pm 1.4$ & $11.1 \pm 1.1$ \\
\hline LVPWT, mm & $10.1 \pm 1.2$ & $10.8 \pm 0.8$ \\
\hline LVEF, \% & $58.2 \pm 10.2$ & $60.3 \pm 5.9$ \\
\hline DES & $(\mathrm{n}=78)$ & $(\mathrm{n}=54)$ \\
\hline $\mathrm{Ch}, \mathrm{mg} / \mathrm{dl}$ & $180.7 \pm 45.1$ & $144.5 \pm 36.8^{* *}$ \\
\hline $\mathrm{TG}, \mathrm{mg} / \mathrm{dl}$ & $195.9 \pm 123.4$ & $139.7 \pm 45.5^{*}$ \\
\hline HDL, mg/dl & $35.9 \pm 6.5$ & $38.8 \pm 7.6^{*}$ \\
\hline VLDL, mg/dl & $39.2 \pm 24.7$ & $28.7 \pm 11.4^{*}$ \\
\hline LDL, mg/dl & $105.6 \pm 35.9$ & $77.7 \pm 25.4 * *$ \\
\hline Glucose, $\mathrm{mmol} / \mathrm{l}$ & $6.6 \pm 2.4$ & $5.3 \pm 1.8^{*}$ \\
\hline CRP, g/l & $23.2 \pm 48.5$ & $3.7 \pm 1.9^{*}$ \\
\hline LVEDV, ml & $150.1 \pm 39.7$ & $147.3 \pm 33.3$ \\
\hline LVESV, ml & $65.8 \pm 26.8$ & $61.4 \pm 15.5$ \\
\hline IST, mm & $10.3 \pm 2.4$ & $10.2 \pm 1.1$ \\
\hline LVPWT, mm & $10.3 \pm 1.4$ & $10.7 \pm 1.1$ \\
\hline LVEF, \% & $57.3 \pm 7.7$ & $61.6 \pm 5.8^{*}$ \\
\hline
\end{tabular}

$*_{-} P<0.05$ and $*_{\text {* }} P<0.001$ (differences between groups) 


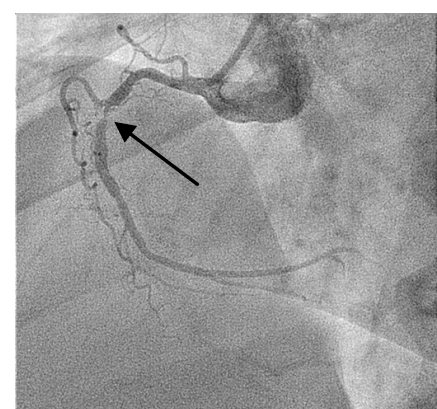

Fig. 3A. SYNTAX Score: 2 points. Initial angiogram of $R C A$. (The arrow indicates stenotic lesion).

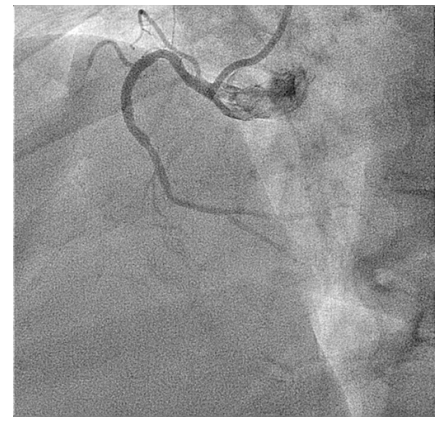

Fig. 3C. Angiogram RKA after implantation of BVS $(3.0 \times 18 \mathrm{~mm})$.

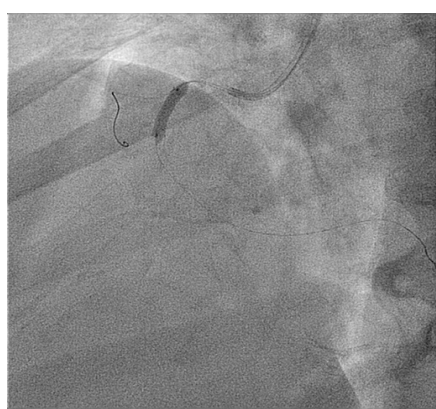

Fig.3B. Inflating.

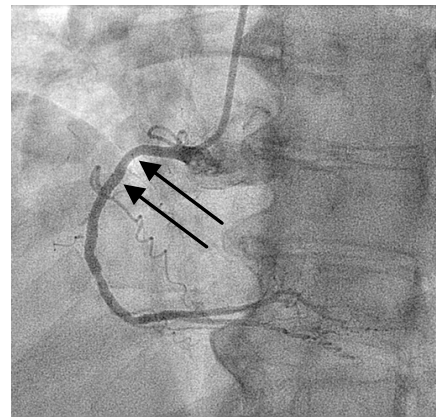

Fig. 3D. Control CAG after 1 year: (The arrows mark the areas of visualization of the carcass marks).
Table 5.

Long-term (12 months) clinical and angiographic results of myocardial revascularization

\begin{tabular}{|l|c|c|}
\hline \multicolumn{1}{|c|}{ Variable } & BVS $(\mathrm{n}=54)$ & DES $(\mathrm{n}=48)$ \\
\hline Heart death & 0 & 0 \\
\hline MI of the target vessel & 0 & 0 \\
\hline Restenosis & 0 & 0 \\
\hline Recurrent / progressive angina & 0 & 0 \\
\hline Stent thrombosis & 1 (after 3 months) & 0 \\
\hline Bioresorption of BVS & 0 & \\
\hline
\end{tabular}

\section{Discussion}

The prospect of using a temporary vascular stent, or biosoluble scaffold, has always been the goal of the intervention community. Such a device must have a radial stiffness to confront the acute collapse of the vessel after the intervention is finished, and must also completely resolve in a distant period, which would restore the biological and physiological properties of the vessel. The Absorb BVS manufactured by Abbott Vascular, Inc. is the first innovative device for the treatment of CAD. It gradually dissolves and is fully absorbed by the body over time. When installed, the BVS first increases the lumen of the artery, and then within 3 months secretes a drug that blocks the process of re-overgrowing the lumen of the artery. Two years later the scaffolds resolve themselves, breaking down into natural components for the body - water and carbon dioxide.

The first study of ABSORB showed impressive results. The main clinical endpoints of this study were the evaluation of the safety and efficacy of the device after 30 days, 6 months, and then every year for 5 years. The results of the first stage established that MACE frequency in 5 years was less than $3.4 \%$. The results of the second stage (duration almost 3 years) also confirmed the efficacy and safety of Absorb in patients with CAD. ${ }^{(10-12)}$ According to our data, MACE frequency (a 12-month evaluation) was $0 \%$. In our opinion, this kind of success was due to strict adherence to the technique of implantation of this type of stent. A BVS has thick striae (beams), which makes it difficult to hold it in the place of constriction. This, in turn, requires not only special surgical skills, but also a certain anatomy of the vessels. In our study, the implantation of BVSskeletons took more time, and they were installed in vessels with a larger diameter (Tables 2 and 3).

ABSORB-II was a prospective, randomized, controlled clinical trial evaluating the safety and efficacy of Absorb BVS as compared to the XIENCEPRIME DES. The study included 500 patients from the centers of Europe and New Zealand. After 1 year, the overall clinical results of the Absorb treatment were comparable to the XIENCE results at a lower revascularization frequency. The incidence of Absorb revascularization was 3.6\% vs. $7.3 \%$ for XIENCE DES $(\mathrm{P}=0.08) .{ }^{(13)}$ The results of our study also show comparability not only for angiographic, but also clinical and laboratory indicators between the BVS and DES groups.

However, the recently available 3-year follow-up data from the ABSORB III study continue to show an increased rate of MACE in BVS patients, when compared to patients implanted with the XIENCE stent. Specifically, there was a 13.4 percent rate of MACE (e.g., cardiac death, heart attack, or the need for an additional procedure to re-open the treated heart vessel) in patients treated with the BVS at 3 years, compared with 10.4 percent in patients treated with Abbott Vascular's approved metallic drugeluting stent, the XIENCE stent $(\mathrm{P}=0.056)$. The ABSORB III study showed a $2.3 \%$ rate of thrombosis within the BVS scaffold versus $0.7 \%$ within the XIENCE stent at 3 years $(\mathrm{P}=0.01){ }^{\left({ }^{(8)}\right.}$

It should be emphasized that these higher adverse cardiac event rates in BVS patients were more likely when the device was placed in small heart vessels. Among BVS-treated patients who developed device blood clots after 1 year, most had discontinued DAT. An additional preliminary analysis of ABSORB III data suggests improved clinical performance and a lower rate of complications associated with BVS implantation when health care providers follow the recommended implantation methods. The FDA-approved labeling for the BVS includes recommendations on selecting appropriately-sized heart arteries for BVS implantation (e.g., avoiding BVS use in small heart vessels) and methods to properly implant the device against the vessel wall. ${ }^{(7,8)}$

Stent thrombosis develops most often during the first month after stenting and, as a rule, ends with Q-wave MI or death of the patient. With gradual improvement of stent implantation technology and mandatory DAT (aspirin+thienopyridine) for 1 month, followed by continued use of aspirin without time limits, the incidence of stent thrombosis decreased to an acceptable $1 \%$. $^{(14)}$

According to the recommendations of $\mathrm{AHA} / \mathrm{ACC} /$ $\mathrm{SCAI},{ }^{(15)}$ aspirin is mandatory during the procedure; however, its dose and duration of administration depend on both the type of stent and the risk of bleeding in the patient. These 2 factors also determine how long the patient should take clopidogrel. At the same time, according to the CHARISMA study, a longer 
DAT does not lead to a reduction in ischemic events among patients with atherothrombosis and persons with risk factors for its development. Such therapy was only accompanied by an increased risk of bleeding. ${ }^{(16)}$ Thus at the present time, the question of the duration of DAT after PCI is open. Based on the data of our own experience, in particular on the abovementioned single case of developing stent thrombosis, we tend to adhere to the tactics of long (at least 2 years) DAT reception. Our study has shown sufficient efficiency of the new scaffold Absorb. Based on the data we obtained, it can be argued that BVS can be used in everyday clinical practice, subject to strict adherence to the basic recommendations for implantation techniques. The reception of DAT should be conducted individually under the control of coagulogram indices.

\section{In conclusion:}

- Implantation ofBVS in patients with different forms ofCAD did not cause any angiographic or clinical complications, either at the hospital or at 12-month observation stages, and the results were comparable to those of the DES group.

- The technique of implanting BVS and the reception of DAT are the key factors for achieving positive results in real clinical practice.

- The use of BVS-frameworks contributes to improving clinical, functional and laboratory indicators, while the observed positive dynamics are comparable to similar data of the DES group.

- Regardless of the type of implanted stents, the survival rate among CAD patients within 12 months after stenting was $100 \%$, while none of the respondents during this time developed acute MI or recurrence of angina attacks.

\section{Competing interests}

The authors declare that they have no competing interests.

\section{References}

1. Ioseliani DG, Arablinskii AV. [Immediate and long-term outcomes of the use of a Crossflex wire coronary stent in the treatment of patients with different forms of ischemic heart disease].Vestn Rentgenol Radiol. 2000(4):11-6. [Article in Russian]

2. Grüntzig A, Hopff H. [Percutaneous recanalization after chronic arterial occlusion with a new dilator-catheter (modification of the Dotter technique) (author's transl)]. Dtsch Med Wochenschr. 1976; 99(49):2502-10, 2511.

3. D'Agostino RB, Russell MW, Huse DM, Ellison RC, Silbershatz H, Wilson PW, Hartz SC. Primary and subsequent coronary risk appraisal: new results from the Framingham Study. Am Heart J. 2000;139(2 Pt 1):272-81.

4. Miller JM, Ohman EM, Moliterno. Restenosis: the clinical issues. In: Topol EJ, editor. Texbook of Interventional Cardiology. Philadelphia: W. B. Saunders; 1999:393.

5. Garg S, Serruys PW. Coronary stents: current status. J Am CollCardiol. 2010; 56(10 Suppl):S1-42. doi: 10.1016/j. jacc.2010.06.007.

6. Nakazawa G, Otsuka F, Nakano M, Vorpahl M, Yazdani SK, Ladich E, et al. The pathology of neoatherosclerosis in human coronary implants bare-metal and drug-eluting stents. J Am Coll
Cardiol. 2011;57(11):1314-22. doi: 10.1016/j.jacc.2011.01.011. 7. U.S. Food \& Drug Administration. FDA Investigating Increased Rate of Major Adverse Cardiac Events Observed in Patients Receiving Abbott Vascular's Absorb GT1 Bioresorbable Vascular Scaffold (BVS) - Letter to Health Care Providers. Available from: https://www.fda.gov/ MedicalDevices/Safety/LetterstoHealthCareProviders/ ucm546808.htm

8. U.S. Food \& Drug Administration. UPDATE on Increased Rate of Major Adverse Cardiac Events Observed in Patients Receiving Abbott Vascular's Absorb GT1 Bioresorbable Vascular Scaffold (BVS) - Letter to Health Care Providers. Available from: https://www.fda.gov/MedicalDevices/Safety/ LetterstoHealthCareProviders/ucm582728.htm

9. Campeau L. Percutaneous radial artery approach for coronary angiography. Cathet Cardiovasc Diagn. 1989;16(1):3-7.

10. Onuma Y, Dudek D, Thuesen L, Webster M, Nieman K, Garcia-Garcia HM, et al. Five-year clinical and functional multislice computed tomography angiographic results after coronary implantation of the fully resorbable polymeric everolimus-eluting scaffold in patients with de novo coronary artery disease: the ABSORB cohort A trial.JACC Cardiovasc Interv. 2013;6(10):999-1009. doi: 10.1016/j.jcin.2013.05.017. 11. Onuma Y, Serruys PW, Muramatsu T, Nakatani S, van Geuns RJ, de Bruyne B, et al. Incidence and imaging outcomes of acute scaffold disruption and late structural discontinuity after implantation of the absorb Everolimus-Eluting fully bioresorbable vascular scaffold: optical coherence tomography assessment in the ABSORB cohort B Trial (A Clinical Evaluation of the Bioabsorbable Everolimus Eluting Coronary Stent System in the Treatment of Patients With De Novo Native Coronary Artery Lesions). JACC Cardiovasc Interv. 2014 Dec;7(12):1400-11. doi: 10.1016/j.jcin.2014.06.016.

12. Costopoulos C, Latib A, Naganuma T, Miyazaki T, Sato K, Figini F, et al. Comparison of early clinical outcomes between ABSORB bioresorbable vascular scaffold and everolimuseluting stent implantation in a real-world population. Catheter Cardiovasc Interv. 2015;85(1):E10-5. doi: 10.1002/ccd.25569. 13. Patrick W. Serruys. ABSORB II : A Prospective, Randomized Trial of an Everolimus-Eluting Bioresorbable Scaffold Versus an Everolimus-Eluting Metallic Stent in Patients with Coronary Artery Disease. TCT 201413 Sep 2014 - 17 Sep 2014 , Washington, DC - U.S.A. Plenary Session XII : Late-Breaking clinical Trials \#2. Available from: https://www.sac.org.ar/wp-content/uploads/2014/09/tct-2014absorb-ii-a-prospective-randomized-trial.pdf

14. Moreno R, Fernández $\mathrm{C}$, Hernández R, Alfonso F, Angiolillo DJ, Sabaté M, et al. Drug-eluting stent thrombosis: results from a pooled analysis including 10 randomized studies. J Am Coll Cardiol. 2005;45(6):954-9.

15. Grines CL, Bonow RO, Casey DE Jr, Gardner TJ, Lockhart PB, Moliterno DJ, et al. Prevention of premature discontinuation of dual antiplatelet therapy in patients with coronary artery stents: a science advisory from the American Heart Association, American College of Cardiology, Society for Cardiovascular Angiography and Interventions, American College of Surgeons, and American Dental Association, with representation from the American College of Physicians. J Am Coll Cardiol. 2007;49(6):734-9.

16. Bhatt DL, Fox KA, Hacke W, Berger PB, Black HR, Boden WE, et al.; CHARISMA Investigators. Clopidogrel and aspirin versus aspirin alone for the prevention of atherothrombotic events. N Engl J Med. 2006;354(16):1706-17. 